\title{
The European project UpTun: results of four years of research to improve the level of fire safety in existing tunnels
}

\author{
H. Hejny \\ Dr. Horst Hejny Consulting, Germany
}

\begin{abstract}
The European economy relies heavily upon a sustainable transportation system. In this transportation system, tunnels are a key element. The safety systems in a significant part of the existing tunnels were designed on the basis of traffic and its estimated growth of two or more decades ago. It appears however that traffic has grown more significantly and also changed in composition (more combustible and flammable goods). Consequently the safety level in existing tunnels has decreased in cases where no intermediate measures were taken to cope with the changed supply of rolling stock. This holds throughout Europe, for road-, rail- and mass-transit tunnels.
\end{abstract}

The UpTun project main objects have therefore been:

- Development of innovative technologies where appropriate and where relevant comparing to and the assessment of existing technologies for tunnel application. Focus is on technologies in the areas of detection and monitoring, mitigating measures, influencing human response, and protection against structural damage. The main output is a set of innovative cost-effective technologies.

- Development, demonstration and promotion of procedures for rational safety level evaluation, including decision support models; and knowledge transfer. The main output is a risk based evaluating and upgrading model.

The desired spin-off of the UpTun project would be:

- The restoration of faith in tunnels as safe parts of the transportation systems;

- The levelling out of trade barriers imposed by supposedly unsafe tunnels;

- An increased awareness of stakeholders for the necessity to develop initiatives to link all relevant research.

This paper will give an overview of the project and the major achievements. Keywords: tunnel safety, fire safety, innovative technologies, tunnel upgrading model. 


\section{Introduction}

The European economy heavily relies upon a sustainable transportation system. In this transportation system, tunnels are a key element. The safety systems in a significant part of the existing tunnels were designed on the basis of traffic and its estimated growth of two or more decades ago. It appears however that traffic has grown more significantly and also changed in composition (more combustible and flammable goods). Consequently the safety level in existing tunnels has decreased in cases where no intermediate measures were taken to cope with the changed supply of rolling stock. This holds throughout Europe, for road-, rail- and mass-transit tunnels.

In addition to this, the accidents in recent years have drawn widespread attention to the risks of fires in tunnels. This has two consequences. First, the fires themselves have resulted in fatalities, casualties and/or economic damage. They have also resulted in lengthy shutdowns of the tunnels themselves. Secondly, the perceived risk of fire is also likely to have discouraged tunnel usage in some cases (tunnels might become an unwanted impediment for trade). Both of these consequences will have added to congestion and hence noise, particulate and airborne pollution with negative environmental and health consequences. As a result of the accidents, and the media attention they have caught, the public acceptance level of fires causing major losses has also decreased.

The main problem statement is now that unsafe, or supposedly unsafe, tunnels hamper the use and the development of sustainable transportation systems, needed in a healthy European economy. Upgrading the safety level in tunnels is, with existing technology and within the legislation and guidelines frameworks of the member states, in most cases, however either nearly impossible or too costly.

Secondary problem is that fire safety is based on a conventional rather than a rational approach. Moreover, fire safety is seldom looked upon in an integral fashion, comprising all aspects (probability of incidents, consequences of fires, human response, structural response, emergency response teams, tunnel operators) in a similar manner. This may result in adverse interaction between preventive mitigating measures or non-optimal safety investments.

\section{The European context of tunnel research}

Several major, high profile and costly tunnel fires have taken place in Europe in the past years that resulted in significant loss of life (about 500 persons) and damage to the structures. Channel Tunnel, Mont-Blanc, Tauern and Kaprun are examples of tunnels where accidents occurred due to fire, thus clearly indicating the inadequacy of current design procedures, that is the main technical limitation of existing tunnels, from technological, methodological and from standards points of view. The costs incurred by Channel Tunnel (in terms of repair costs and loss of business from lengthy closure of the tunnel) amounts to some 82 million Euro. Therefore several tunnel safety projects were launched. 
All of these projects have been designed in a complementary way with only very few overlapping. The projects, the finished or still running ones as well as other activities of PIARC, ADAC or OECD fit together like the pieces of a puzzle.

Furthermore, significant results are achieved from research project and incidents in the past like SAFESTAR; FIRESTARR or FIRETUN as well as the MEMORIAL TUNNEL; OSIS and the conclusion from severe tunnel fires in Storebælt, Channel Tunnel, Mont-Blanc, Tauern and Kaprun.

The focus of these has been on life safety issues, emphasising the conditions developing in a tunnel under fire and by ventilation control. Limited work is available on design scenarios for fire, any mitigation measures or human response factors. Major knowledge gaps exist in evaluating these matters, how to implement them and to upgrade the safety of existing tunnels. Fire safety tools in general are developed for buildings and industrial plants, which are not always cost efficient when applied in tunnels. Upgrading of tunnel safety may need expensive installation or even construction work; therefore it was necessary to develop cost efficient innovative means for existing tunnels.

\section{Description of the UpTun project and achievements}

The UpTun project (Cost-effective, Sustainable and Innovative Upgrading Methods for Fire Safety in Existing Tunnels) had two main areas of activities:

1. Assessment of existing technologies for tunnel application and development of innovative technologies where appropriate. Focus was on technologies in the areas of detection and monitoring, mitigating measures, influencing human response, and protection against structural damage.

2. Development of procedures for safety level evaluation, including decision support models; and knowledge transfer

These activities have been organised in six coherent work packages; the management of the project defines one additional work package. This lead to the following list of work packages:

Workpackage 0: Project Management

Workpackage 1: Prevention, detection and monitoring

Workpackage 2: Fire development and mitigation measures

Workpackage 3: Human response

Workpackage 4: Fire effects and tunnel performance: system structural response

Workpackage 5: Evaluation of safety levels and upgrading of existing tunnels

Workpackage 6: Fire effects and tunnel performance: system response

Workpackage 7: Promotion, dissemination, education/training, and socioeconomic impact

Within each of the workpackages, specific tasks were dedicated to ensure cross-beneficial interrelations with ongoing and future relevant projects. The UpTun project has addressed all types of tunnels; where relevant in sub-tasks, a distinction was made between road and rail tunnels. 


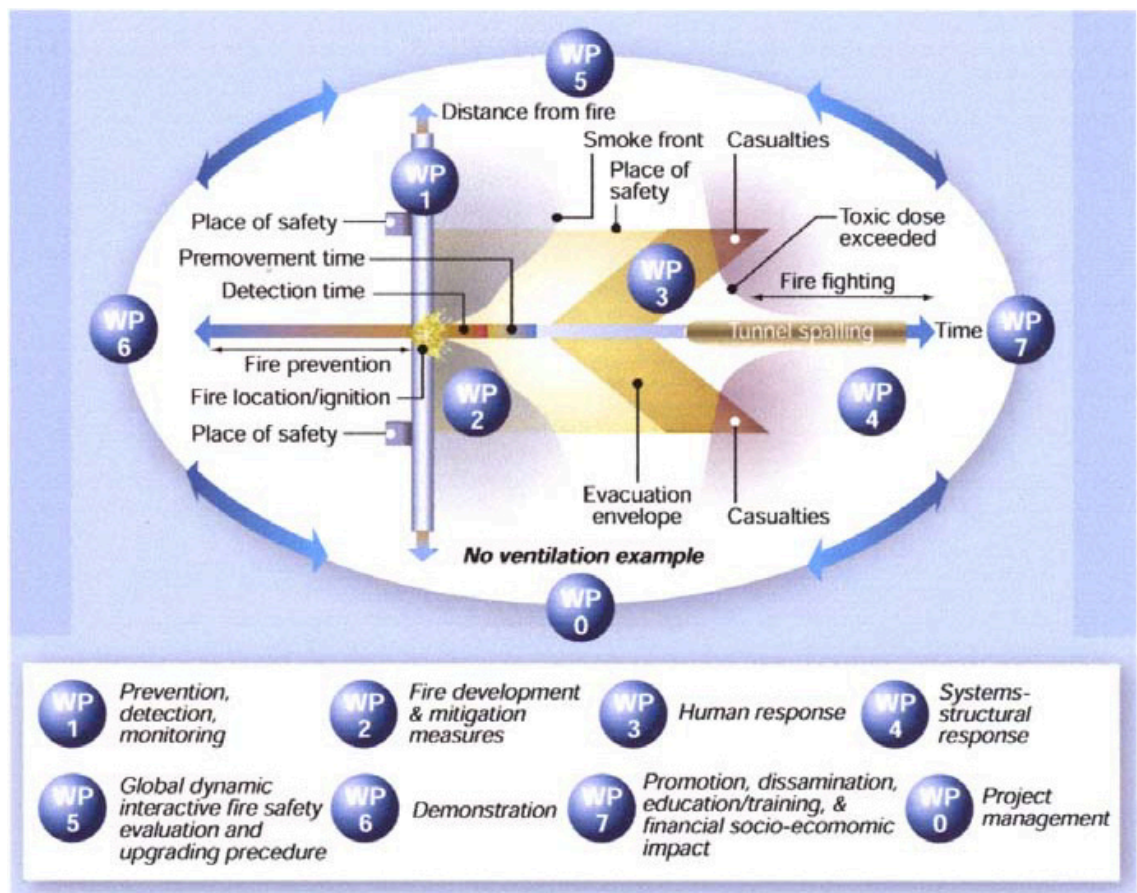

Figure 1: UpTun project overview: roles of individual item workpackages and global workpackages.

Figure 1 shows where the work packages interact with a tunnel incident. The graph contains the location of the smoke front in an axis system with time on the $\mathrm{x}$-axis, and distance to the fire source on the $\mathrm{y}$-axis. Also shown is the position of people escaping towards emergency exits on both sides of the fire source. The graph shows how people starting their escape too late are overtaken by the smoke front, and where structural damage fits in. Similar graphs can be drawn up to show the influence of mitigating measures such as ventilation and fire suppression on the danger to life and on structural damage. The main objective of the figure is to show where the different work packages interact with the incident.

The project consortium comprised of 41 partners from 18 European counties. The coordinator was TNO from the Netherlands. The partners came from all over Europe and the consortium showed a good balance between industry, consultancy, research institutes and universities.

This consortium worked for four years (September 2002 until August 2006) to solve open questions and develop innovative technologies related to fire safety in existing tunnels. The project volume was about 12 million $€$ with $50 \%$ funding from the European Commission. The amount of work foreseen had a total of about 950 man-months, which are roughly 80 man-years. 


\subsection{Technical approach}

The problem of upgrading existing tunnels in terms of fire safety was handled in a holistic way. Safety of tunnels is affected by all kinds of mitigation measures (monitoring, detection, suppression, traffic control) as well as tunnel layout and structural questions. Consequently all mentioned parts of a tunnel as well as questions on human behaviour have been investigated.

The overall aim to develop suitable upgrading recommendations for existing tunnels was achieved by evaluating existing measures and developing innovative ones. All measures were evaluated in terms of their contribution to cost effective safety upgrading of tunnels. This was carried out using laboratory to just medium-scale experiments accompanied by numerical calculations. In addition the upgrading efficiency of a set of upgrading measures was demonstrated in a real tunnel.

Close co-operation with other ongoing projects on tunnel safety issues and the advisory group of UpTun as well as the exchange of information ensured to avoid overlapping in work and a co-ordinated approach towards the aim.

Daily operation of rail and road tunnels is very different and any rescue operation especially. UpTun has therefore distinguished between the tunnel types in addressing these issues.

The main emphasis of the project work was on innovation. Innovation, through research and development, is what distinguishes the UpTun project from its sister European funded projects. Innovation in UpTun can be divided into two categories:

- Innovation relating to individual tunnel fire safety features (e.g. fire suppression)

- Innovation relating to the fire safety of the tunnel as an integral unit (holistic approach)

Given that innovation is unpredictable in nature, the UpTun project has developed a strategy and structure for innovation based on the above two categories. It is important to introduce innovative ideas from the outset in the project proposal and ensure that the expertise and budgets for these innovations are available within the project. Furthermore, innovation was introduced into each and every work package and not just confined to a certain number of work packages. This insured that all aspects of fire safety in tunnels are included in the innovation process of UpTun, from detection of the fire at its earliest stages to its full consequences, including fire mitigation, human response, structural response and overall evaluation of fire safety of an individual tunnel.

What distinguished this project from all preceding investigations was its scale and comprehensive integrated innovative approach aiming at an overall solution to this important problem. To this end, new hardware and procedures were developed. While all aspects of fire safety in tunnels are important, special emphasis was placed upon fire detection and suppression and smoke control in the early stages of the fire, this being the key "golden hour" stage of the development of tunnel fires. 
By far, the majority of tunnels in Europe rely upon ventilation for smoke control. Fire detection of moving fires (e.g. on trains) and fire suppression is an area requiring development. With this philosophy, innovative features such as the water mist fire suppression system and the air-plug fire-smoke suppression system have been incorporated into the project. The air plug innovation was a result of lateral thinking from a totally different field, namely fabric engineering as applied in, for example, the manufacture of hot-air balloons. To ensure that the know-how and manufacturing capability are available "in-house", innovative SME's were made a partner in the project.

The following paragraphs give a short summary of the UpTun achievements in more detail related to the different aspects of fire safety in tunnels. It has to be noticed that this paper can only give a summary of the UpTun results. Details on particular results are available on request.

\subsection{Fire detection}

In case of an incident, and actually prior to that, first thing is to gather information. Innovations have been developed to detect fire and smoke, and adequately linking the detection to active measures to control smoke development and/or the fire. Furthermore, innovation is also put in new detection methods for people and for vehicles or rolling stock, both stationary and moving.

Any measure on the level of installation or operation (guiding evacuees, emergency response service) should be based on actual information regarding the location (whereabouts: duplication in working) of the fire and the distribution of smoke, its anticipated development based on knowledge of type and mass of the combustibles and the whereabouts of users.

Within the UpTun project a comprehensive effort was undertaken to gather and adequately link this information for further decision support. The main aim was to reliably detect fire and smoke within 2-5 minutes, because of the likelihood of fire scenarios with rapid developing fires.

The main achievement in this context was an algorithm for detection of smoke and fires, especially moving fires by processing the images coming from CCTV. This algorithm reliably detects moving fires within only a couple of seconds. This enables quick response of the emergency teams in order to avoid serious damages.

\subsection{Fire mitigation}

Fires can probably never be completely excluded in daily operation. Mitigation measures are therefore inevitable. To date, safety designs rely on well developed ventilation systems for smoke control and passive fire protection through thermal barrier systems with a view to limit damage to the structure. Innovation in this field has focused on other measures, with respect to smoke compartmentalization and fire growth limitation.

Outstanding results have been achieved concerning fire scenarios in largescale tests carried out in the Runehamar tunnel in Norway. Real-scale lorry loadings of furniture as well as of artificial material compositions have been 
burnt in a lorry mock-up. Heat release rates of unexpected values up to $300 \mathrm{MW}$ were obtained. The results showed that the current design fire assumption should be revised.

Suppression systems installed in open and well-vented tunnels are very unusual due to the high cost involved and due to the lack of validation of mitigation effects. However, water mist in enclosed spaces has become very successful as a Halon replacement during the last 10 years. The advantage of use of water mist is much less water consumption than deluge systems and it can be released directly into the fire zones, with few negative effects on occupants. A high-pressure water mist systems was investigated in the frame of the project. It showed capability of significantly reducing the fire size, which contributes to the protection of the tunnel structure and of course also the tunnel users.

An alternative system was investigated based on fabric technology. An air plug was developed which when inflated in a tunnel will prevent smoke from reaching people and oxygen from reaching the fire (see figure 2). Several air plugs may be required along the tunnel placed in the tunnel crown at key locations along the tunnel. On trains, air plugs could be placed at the end of each carriage to isolate a fire to one carriage only. Air plugs inflate at a reasonable rate (not too fast or too slow) and being made of fabric do not cause injury to people or damage to infrastructure. The logistics and mechanics of air plugs were developed in this project to ensure their safe and effective operation.

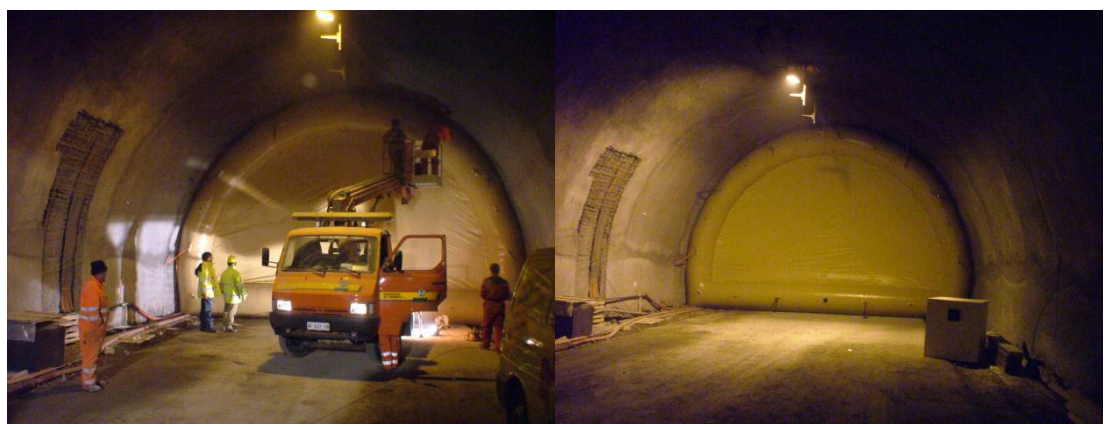

Figure 2: The air plug installed in the Virgolo tunnel during demonstration tests.

A third system under investigation was the so-called water curtain (see figure 3). Similar to the tunnel plug a water curtain should prevent smoke from reaching people. The system is designed in the way that it provides easy access of the response teams to the fire zone and acceptable working conditions by cooling down the fire and at the same time avoids oxygen depletion.

Extensive tests have revealed promising results for water-curtains and to a certain degree also for inflatable plugs to control smoke spread as well as for high-pressure water-mist suppression systems to limit fire growth. 

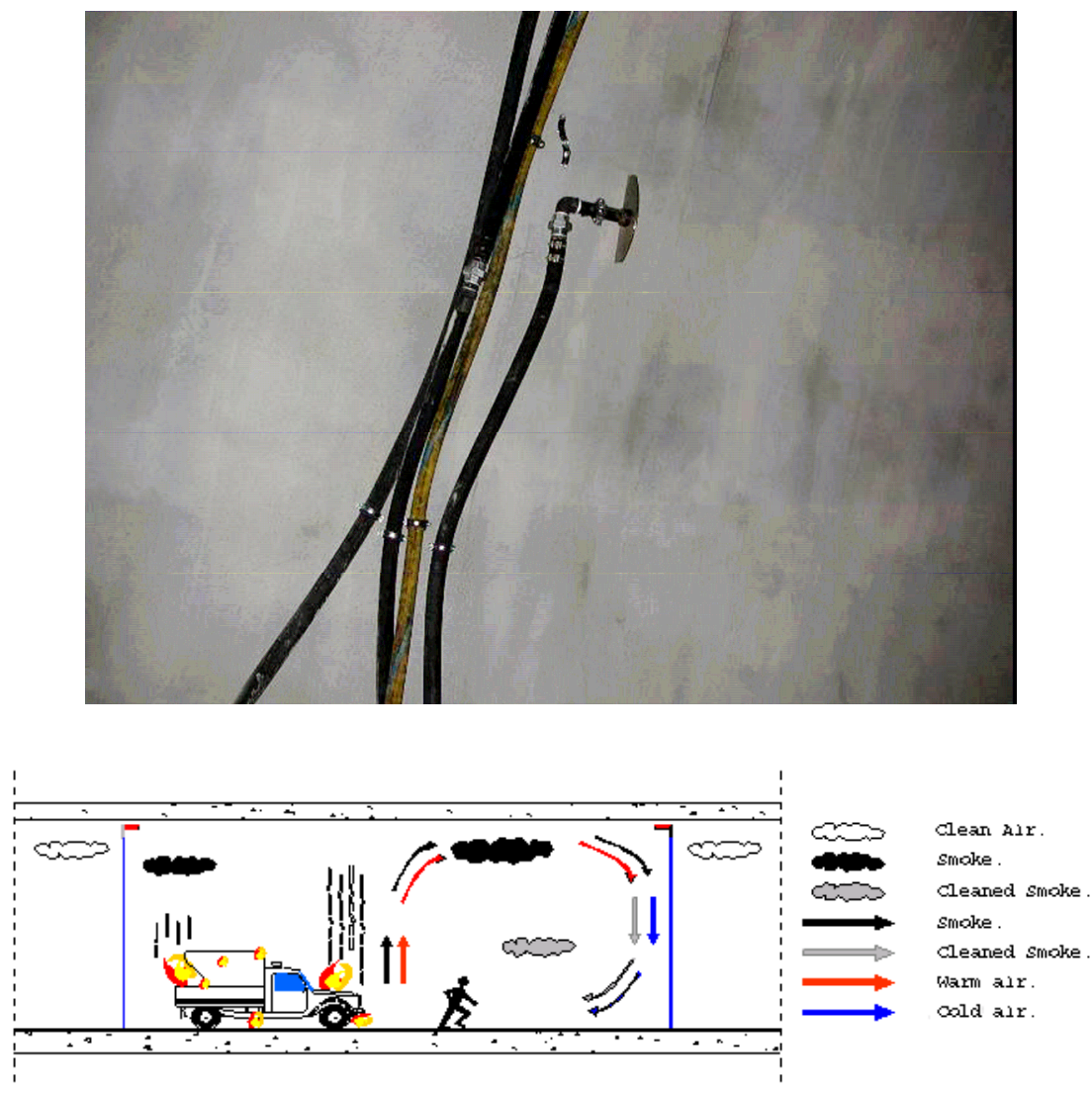

Figure 3: Nozzles and principle of the water curtain system.

\subsection{Human response}

Human behaviour is an essential factor in tunnel safety. This counts not only for the users, but also for the operators and emergency response teams.

Extensive studies have been performed, using a car and a truck driving simulator. Crowds have been studied in evacuation exercises resulting in the establishment of an innovative egress model and innovations were developed to facilitate evacuation (dynamic guidance based on actual temperature and atmosphere monitoring and on the basis of advanced lighting systems combined with sound beacons, see figure 4).

Through these innovations, substantial improvement in evacuation can be achieved. Furthermore, concrete results allow for an upgrading of operator rooms and offices. Finally studies have unravelled the complexity of tasks and interference of emergency response services (medical and fire fighting); concrete recommendations are at hand for fine-tuning combined operations in the aftermath of incidents. 


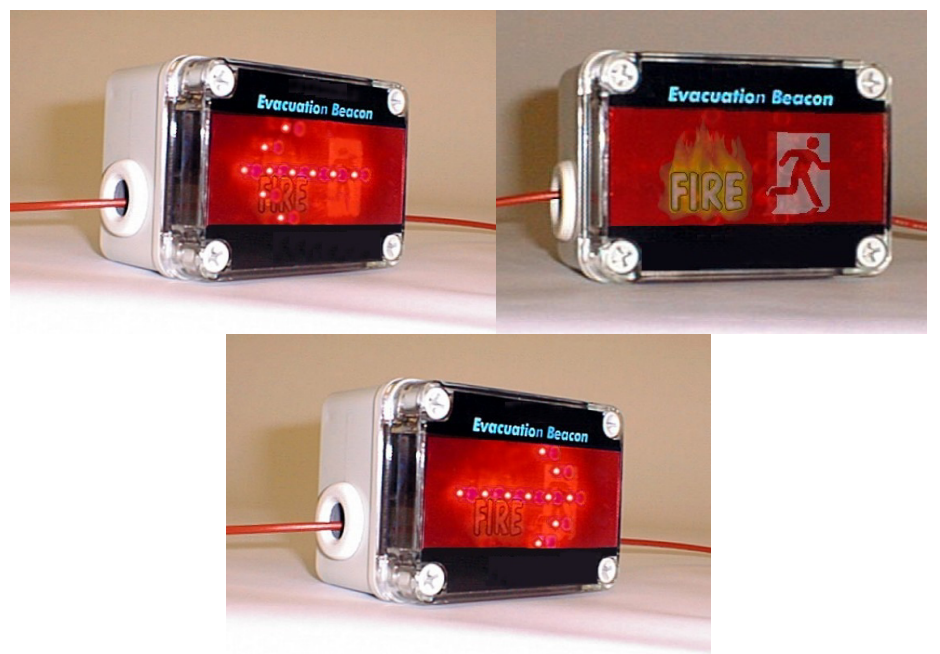

Figure 4: $\quad$ Innovative evacuation device.

\subsection{Structural response}

One of the main structural problems in tunnels exposed to fire is the serious damage caused by explosive spalling of the concrete (e.g. Channel Tunnel, Great Belt Tunnel, Mont Blanc Tunnel). While recent developments have made progress in this area, the subject is not fully understood and solutions not optimised.

Once a fire reaches a certain size, without adequate measures, significant damage may occur. With a view to assess the damage level and to quickly and cost-efficiently repair the damage, new computer aided assessment techniques have been developed as well as advanced concrete mixes for repair works. This will allow substantial reduction in non-operational time after an incident.

The main achievements in the context are new damage investigation methods and repair and recovery procedures including new repair material compositions, a review of explosive spalling and a spalling assessment and design tool (HITECOSP 2).

\subsection{Holistic-dynamic evaluation and upgrading model}

In relation to the holistic approach, a new model was developed from the fields of artificial intelligent and expert systems to ensure that a holistic evaluation and upgrading procedure was developed for existing tunnels with the important output being the fire risk profile that would allow a financial and socio-economic assessment to be made. Even in the socio-economic analysis, innovation was introduced and developed from a Nobel Prize winning theory.

With a view to assist designers and exploiting institutes or companies, as well as owners of tunnels, the advanced integrated model developed, links technical sub-models as well as (socio-) economic models, on the basis of 
modern and new artificial intelligence computer architecture. The integrated model will allow for easy (geometry and other) data input, facilitating optimized upgrading of a certain specific tunnel, through intelligent and cost-efficient balancing of different (combinations of) fire safety measures.

All innovations are introduced in this task which brings together the results on individual features in a global evaluation and upgrading model. These are listed as follows:

- Modelling the influence of suppression system on fire-smoke development.

- Risk assessment of system-structural response

- Dynamic modelling of the human consequences for possible fire developments in the tunnel

- Use of constraint programming to optimise the number of options from the model.

- Use of expert systems.

- Use of logarithmic addition theory to optimise on safety levels

- Development of fire risk profiles for a tunnel as a whole for input into socio-economic model.

- Socio-economic model

\subsection{Demonstration tests}

Promising demonstration upgrading tests have already been carried out in the beginning of 2005, amongst other in the upgraded (first bore of the) Virgolo tunnel in Bolzano, part of the Brenner Highway in Italy. Figure 5 shows the arrangements of the fire sources.

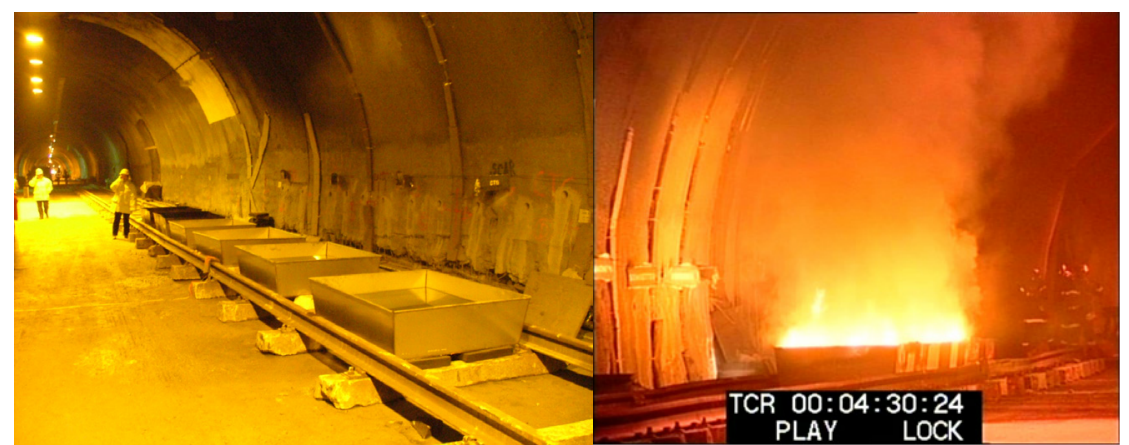

Figure 5: Demonstration tests in the Virgolo tunnel, Bolzano, Italy.

\subsection{Dissemination}

Extensive knowledge transfer measures have been developed. E.g. summer- and other courses have been prepared, to allow the existing as well as the new generation of tunnel safety involved parties to profit from the UpTun findings. In the autumn of 2006, a first full extensive course took place in Pavia, Italy. 


\section{Large scale problems (L-surF)}

If one thing has become apparent from the EU co-financed projects such as UpTun and other projects like DARTS (Durable And Reliable Tunnel Structures; www.dartsproject.net) and FIT (Fire In Tunnels; www.etnfit.net), it is that accurately assessing the safety level of complex systems such as tunnels on the basis of laboratory tests on sub-systems and single elements, even in combination with advanced modelling techniques (CFD, FEA), is hardly possible. This is (a. o.) due to:

- $\quad$ Scale effects

- Unexpected (adverse or positive) interaction between (mitigating) measures

- $\quad$ Limited (read: costly) options to validate models to realistic scale events

- Not well understood or even unknown physical phenomena regarding fire development (spread of fire to other vehicles or rolling stock)

Research on safety and security in enclosed underground spaces is of outstanding importance as current incidents (tunnel fires, terror attacks in metros etc) have shown. However, currently the EU competence related to safety and security is largely unstructured, fragmented and mostly national oriented. Especially missing is a large scale research facility and the coordination and synergy of existing facilities. The necessity for a European wide initiative in these respects also was identified and clearly expressed during the 1st International Symposium on Safe and Reliable Tunnels, held in Prague in February 2004.

Leading (fire)safety, security and tunnel construction institutes in Europe have joined forces to develop a versatile research facility, enabling full scale investigation of (combinations of) safety and security measures, not only for tunnels, but for the full spectrum of underground facilities (parking, buildings,

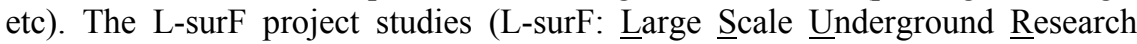
Facility):

- The constructional lay-out of the research facility, based (if the concept is feasible) on an entirely new concept for easily creating any contours, shapes and sizes of enclosed spaces needed, but also all other aspects like installations, environmental impacts etc. The concept will allow novel approaches to R\&D work

- Innovative measuring sensors, based on the latest technologies (e.g. nanotechnology) available

- The most urgent research needs

- An integration process for the existing and projected national facilities with their competences and researchers, thus restructuring and improving the relevant EU competence while simultaneously showing ways for using R\&D funds more economically

L-surF is also about security (terrorist attacks on underground and/or enclosed spaces, e.g. the recent attacks in London) because there are similarities in the effects (casualties, fire, smoke, lack of orientation, questions of evacuation, safety of construction etc) and the need for large scale testing is given also there. 
Furthermore, L-surF also responds to the European strategic initiative on safety and security; these two facts underline the importance of L-SurF.

In due time, L-surF will bundle the strengths of the initiating partners, providing a full range of services, which besides full scale testing includes training and education and will also act as an integrating nucleus for panEuropean activities on safety and security in underground spaces. Readers are invited to visit the L-surF website (www.l-surf.org), also with a view to respond to questionnaires regarding the necessity for research in this field and/or to declare interest in participating in some form to the L-surF initiative.

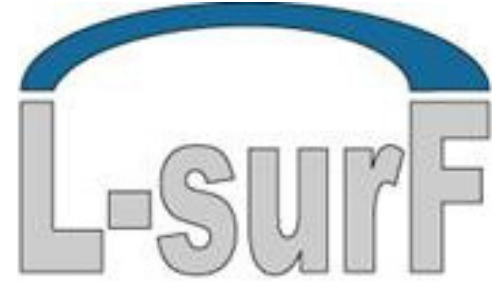

Figure 6: The L-surF logo.

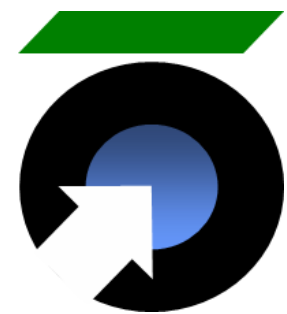

Figure 7: The ITA-COSUF logo.

\section{Internationalisation}

Transport and reliable infrastructure are global problems. The chairmen and coordinators consortia of the projects mentioned above in this article, together with others, have discussed with ITA and PIARC to establish an international permanent body for addressing safety of underground facilities.

As a result, the ITA has adopted the idea and a Committee on Operational Safety of Underground Facilities - COSUF has officially been established in Lausanne in May 2006, under the chairmanship of Prof. Alfred Haack. The scope of the Committee is devoted to safety and security in tunnels and underground facilities in operation. The Committee aims to maintain the existing networks (as established in the EU-projects), to encourage collaboration and to facilitate a worldwide co-operation. It is the Committee's ambition to contribute to and to promote tunnel safety by fostering innovation, raising awareness and to support the development of regulations.

The committee will initiate ad-hoc teams to address issues related to safety and to focus on international research programs and groups (e.g. 7th Framework Programme on Research and Technical Development of the EU and ECTP European Construction Technology Platform). A website, based on the FITwebsite with its databases, is being developed.

Thus, tunnel fire safety will be closely monitored and watched, and kept on the agenda of stakeholders, with a view to coordinate efforts, technology, expertise and means for optimum safety of end-users allowing safe and reliable transport of people and goods. 


\section{Conclusions}

The UpTun project was very successful in providing innovative results and solutions related to tunnel fire safety. This paper was only able to give a comprehensive overview without explaining individual achievements in more detail. The reader is kindly referred to the UpTun web site (http://www.uptun.net) for more information. Most of the reports and papers will be made available soon. The author also offers to facilitate more detailed information and contacts.

Thanks to the establishment of ITA-COSUF the UpTun achievements have an international platform for further dissemination. Thus, tunnel fire safety will be further monitored and watched, and kept on the agenda of stakeholders,

\section{Acknowledgements}

The UPTUN-project 'Cost-effective, sustainable and innovative upgrading methods for fire safety in existing tunnels' has been carried out in the framework of the 'Competitive and Sustainable Growth Programme (project GRD1-200140739, Contract G1RD-CT-2002-0766), with a financial contribution of the European Community.

\section{References}

[1] Both, C., Haack, A., Lacroix, D., Upgrading the fire safety of existing tunnels in Europe: a 13 M EUR European research project. Proceedings ITA World Tunnelling Congress 2003 '(Re)Claiming the Underground Space', 12-17 April 2003, Amsterdam, edited by J. Saveur, volume 1, pp. 239-244 (ISBN 905809543 6).

[2] Khoury, G. EU tunnel fire safety action. Tunnels \& tunnelling International, April 2003, pp. 20-23.

[3] Brekelmans, J. Tunnel safety-related research projects and networks funded by the European Commission. PIARC 22nd World Road Congress 'Connecting the World', 19-25 October 2003, Durban.

[4] Khoury, G., Both, C. European action on fire safety in tunnels. Fire \& Rescue, January 2004. pp15-18.

[5] Khoury, G., Majorana, C. European action on fire safety in tunnels. World Tunnelling, February 2004, pp. 18-21

[6] Cristani, M., Khoury, G., Majorana, C. The control of Upgrade Activities for Long Tunnels by an Intelligent System, The Seventh International Conference on The Application of Artificial Intelligence to Civil and Structural Engineering, Netherlands, 2-4 September 2003.

[7] Haack, A., Latest Achievement and Perspectives in Tunnel Safety, 30 ${ }^{\text {th }}$ ITA-Conference in Singapore, 22. - 27.5.2004

[8] Hejny, H. Sicherheit in Tunneln - Ein Europäisches Ziel, VIATEC 2004, Internationaler Kongress: Die Straßeninfrastruktur, Innovation und Sicherheit, Bolzano/Bozen, Italy, 30.09 - 01.10.2004 
204 Safety and Security Engineering II

[9] Khoury, G. EU tunnel safety update. Tunnels \& tunnelling International, February 2005, pp. 41-43.

[10] Khoury, G., Molag, M. Actual time tunnel safety - A new approach. Tunnels \& tunnelling International, July 2005, pp. 46-48.

[11] Hejny, H. The European Project UpTun - Improving the Level of Fire Safety in Existing Tunnels. SAFE 2005, First International Conference on Safety and Security Engineering, Rome, Italy, 13 - 15 June 2005

[12] Both, K., Haack, A., Hejny, H. Tunnel safety: partnership in Europe provides innovations and new collaboration. 2nd International Symposium on Tunnel Safety \& Security, Madrid, Spain, 15 - 17 March 2006 